\title{
What We Learned When We Compared Discussion Posts from One MOOC Hosted on Two Platforms
}

\author{
Rebecca M. Quintana \\ University of Michigan, USA \\ Juan D. Pinto, \\ University of Illinois at Urbana-Champaign, USA \\ Yuanru Tan \\ University of Wisconsin-Madison, USA
}

\begin{abstract}
We compared discussion posts from a data science ethics MOOC that was hosted on two platforms. We characterized one platform as "open" because learners can respond to discussion prompts while viewing and responding to others. We characterized the other platform as "locked" because learners must respond to a discussion prompt before they can view and respond to others. Our objective is to determine whether these platform differences are consequential and have the potential to impact learning. We analyzed direct responses to two discussion prompts from two modules located in modules two and six of an eight module course. We used conventional content analysis to derive codes directly from the data. Posts on the "open" platform were characterized by failure to completely address the prompt and showed evidence of persuasion tactics and reflective activity. Posts on the "locked" platform were characterized by an apparent intent to complete the task and an assertive tone. Posts on the "locked" platform also showed a diversity of ideas through the corpus of responses. Our findings show that MOOC platform interfaces can lead to qualitative differences in discussion posts in ways that have the potential to impact learning. Our study provides insight into how "open" and "locked" platform designs have the potential to shape ways that learners respond to discussion prompts in MOOCs. Our study offers guidance for instructors making decisions on MOOC platform choice and activities situated within a learning experience.
\end{abstract}

Keywords: online learning, discussion forums, discussion boards, usability

Quintana, R. M., Pinto, J. D., \& Tan, Y. (2021). What we learned when we compared discussion posts from one MOOC hosted on two platforms. Online Learning, 25(4), 7-24.

DOI: $10.24059 /$ olj.v25i4.2897 
In both face to face and online learning contexts, discussion is a key aspect of social learning (Cohen et al., 2003; Conole, 2014; Kellogg \& Oliver, 2014). Within the context of Massive Open Online Courses (MOOCs), fostering rich social interaction is challenging, because features of MOOC platforms are limited, and instructors must rely on discussion forums as a primary space for learners to interact (Almatrafi \& Johri, 2018). There are other potential challenges associated with fostering meaningful peer-to-peer interaction within MOOCs, including low participation rates (Bruff et al., 2013), limited instructor involvement in discussions (Chandrasekaran et al., 2015), and interface usability issues (Azhar \& Santoso, 2019). Scholars have noted that the chaotic structure of forums can create a disjointed experience for learners who must piece together fragmented threads (c.f., Almatrafi \& Johri, 2018). Other research has shown that most discussion forum posts serve to highlight information acquisition, rather than critical thinking (c.f., Bonafini et al., 2017). Yet, despite these known limitations, MOOC instructors continue to use forums for discussion-oriented activities because they offer opportunities for learners to respond to open-ended prompts and engage in higher order cognitive tasks (Ferguson \& Sharples, 2014).

The question at the heart of this study is how might differences in MOOC platform interfaces influence discussion post characteristics? A related question is if MOOC platform interfaces have the potential to shape discussion posts, how might these differences matter for learning? MOOC discussion forum interfaces differ in important ways. Notably, on platforms whose discussion forums we would characterize as "open," learners are shown discussion prompts alongside responses that learners have already given. This provides learners an opportunity to peruse the responses of others before submitting one of their own. On platforms that we would characterize as "locked," learners are shown a discussion prompt and must submit a response before they can view and respond to the posts of others. Given that there are such differences, research is needed to understand ways in which platform interface differences are consequential to the learning experience. A deeper understanding of these outcomes could influence platform choice from the outset. Once the platform is selected, research findings could guide the selection and creation of learning activities for specific platforms.

To explore this issue, we qualitatively examined discussion posts of learners who enrolled in a data science ethics MOOC offered on two platforms: edX (edX Inc., 2020) and Coursera (Coursera Inc., 2020). The course design was the same in every respect (i.e., all lecture videos and discussion prompts were identical), except that some learners took the course on edX and others took it on Coursera. Building on earlier studies of this MOOC that showed differences in interaction patterns in discussion forum activity across platforms (Tan \& Quintana, 2019; Tan et al., 2020), the present study investigated how platform interfaces may influence qualitative aspects of learners' responses to discussion posts. Specifically, we sought to understand how learners responded when they were shown an active discussion forum prior to submitting a response (i.e., on edX) compared to learners who were not shown an active discussion forum prior to submission (i.e., on Coursera). Throughout this study, we called the edX interface "open" and the Coursera interface "locked." Our study consisted of a content analysis and did not require us to alter the platform interfaces in any way. All discussion forums were "open" on edX and "locked" on Coursera by default or by virtue of interface design decisions made by platform providers. MOOC instructors and learning experience designers did not have the ability 
to alter these interfaces, setting them to "open" or "locked." Furthermore, the data science MOOC discussion prompts did not request that learners respond to their peers; instead, the prompts offered learners an open-ended question that focused on a data science issue raised in the lecture materials.

Figure 1 illustrates differences in the user interfaces that learners used to interact with discussion prompts on edX and Coursera, respectively.

Figure 1

Platform differences between Coursera and edX.
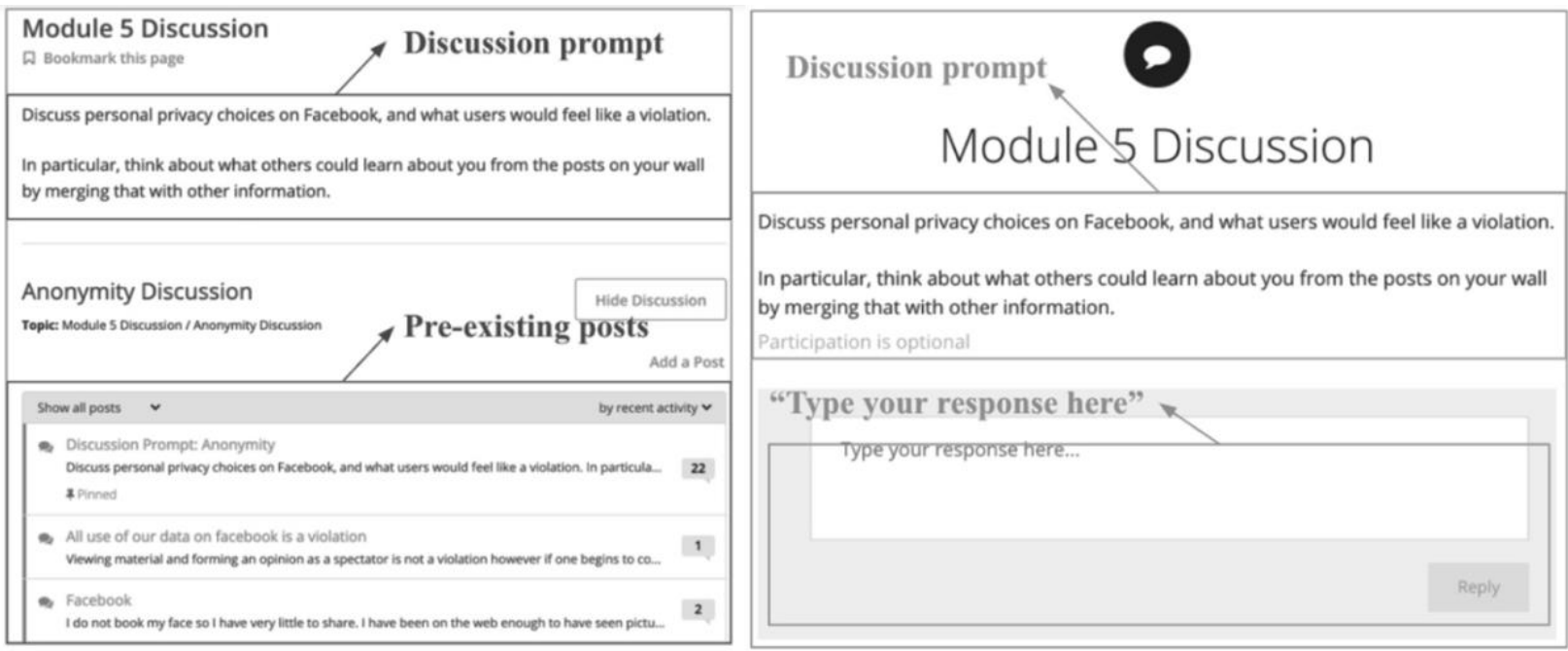

Note. The differences in the way that learners interact with discussion prompts on edX and Coursera. Left: On edX (open), pre-existing posts are visible to learners before they respond to a prompt. Right: on Coursera (locked), learners are asked to respond to the prompt without seeing historic posts.

\section{Literature Review}

MOOCs have long been associated with individualistic models of instruction and transferoriented pedagogies (Eisenberg \& Fischer, 2014). Although some early MOOC designs (i.e., cMOOCs) promoted collectivist approaches and constructivist pedagogies (c.f., Downes, 2009), the xMOOC model is by far the most dominant type of MOOC, and its associated pedagogies (i.e., transfer-oriented, self-paced) are reinforced by platform affordances. While some design efforts have been made to create opportunities for deep learning in large-scale, open access learning environments through the advancement of community-oriented instructional models (c.f., Quintana et al., 2020; Håklev \& Slotta, 2017), these efforts have largely focused on pedagogical decisions within the course, including careful placement of instructional items within a course sequence (Quintana \& Tan, 2021), development of co-dependent activity structures (Emmanuel \& Lamb, 2017), and creation of effective participant structures (Quintana et al., 2020). Since MOOC discussion forums remain the primary mode of learner-to-learner interaction within at scale learning environments, more research is needed to understand how learners use platform affordances to respond to discussion prompts and to engage with peers. Our literature review elucidates how learners' use of discussion forums has changed over time revealing new challenges associated with their use. We also describe existing research on the user interface design within MOOCs and situate the present study within prior research on dual platform comparisons and qualitative analysis methods used in the context of MOOC discussion forums. 
Recent studies by learning analytics scholars have identified trends in learners' use of MOOC discussion forums that shed light on possible challenges associated with their continued use. Poquet et al. (2018a) found that over multiple iterations of the same MOOC categories of learners tended to remain consistent (e.g., drop-ins, occasional posters, hyper-posters), while group activity has generally decreased. This suggests that learners are losing interest in using discussion forums to create social spaces for learning. Research on how learners perceive social presence in MOOCs supports this assertion. For example, Poquet et al. (2018b) found that learners generally reported higher social presence scores in smaller courses, though all MOOC learners - regardless of course size - experienced a low sense of familiarity, emotional connection, and trust. Both studies show that a variety of factors can influence learner behavior in discussion forums, including their perceived usefulness as a social space for learning and perceived social presence relative to cohort size.

Existing research on MOOC platform design has thus far focused mostly on user experience design, including studies that use heuristic evaluation techniques to identify interface problems on individual MOOC platforms (Glory et al., 2019; Hanifa et al., 2019). With respect to user experience design, Hanifa et al. (2019) evaluated the Coursera MOOC platform using Shneiderman's (1997) interaction design principles and Gagné et al.'s (1992) principles of instructional design. Concerning discussion forums, Hanifa et al. (2019) made recommendations to increase the visibility of the entry field for direct responses and to minimize entry fields for replies. Glory et al. (2019) evaluated the edX platform following the same criteria adopted by Hanifa et al. (2019) and reported that the "add a post" and "add a response" buttons on edX discussion forums could be more self-evident if they were repositioned on the interface. Research that compares MOOC platforms has also focused on usability (c.f., Tsironis et al., 2016) and user satisfaction with respect to how various platform features support learning activities (Oktavia et al., 2018). Such usability and user studies do not shed light on the intersection of platform design and learning.

The present study examined the same data science ethics MOOC studied by Tan $\&$ Quintana (2019) and Tan et al. (2020), who focused on how learner interaction might differ across MOOC platforms using social network analysis and clustering analysis methods. These two studies in combination revealed that learners on the edX platform who were more interest driven as indicated in their responses in the pre-course survey demonstrated higher engagement in discussion forums than learners on Coursera, who were more motivated by career advancement. Building on this earlier work (Tan \& Quintana, 2019; Tan et al., 2020), the present study aimed to scrutinize the content of learners' discussion posts and so qualitative approaches must be considered. Although qualitative methods are rarely used in at-scale learning environments, Wong et al. (2015) provide an example of qualitative methods being used to identify the types of knowledge exchange associated with Bloom's taxonomy occurring in a MOOC discussion forum. Dowell et al. (2018) used group communication analysis methods to understand how the frequency of posting activity might influence the quality of MOOC discussion posts. They found that increased posting activity correlated with reduced quality of conversation, and vice versa. Such qualitative approaches to analysis are more commonly found in formal higher education contexts that are not implemented at scale. For example, Hara et al. (2000) found that students' conversations that exhibited higher order cognition usually contained explicit references to peers' posts based on a qualitative content analysis of a graduate level psychology course's asynchronous discussion forum. In another example, McLoughlin and 
Mynard (2009) used qualitative content analysis to identify evidence of higher-order thinking processes in a 20-week semester undergraduate online discussion forum. We similarly used qualitative content analysis in this study, though we did so to compare learner discussions on two distinct MOOC platforms. We detail the specifics of our data set and approach to analysis in the Methods section below.

For the present study, our objectives were to provide instructional teams with findings to support decision-making around platform choice and to enable them to tailor discussion activities based on platform affordances.

To meet the stated objectives, we pursued the following research questions:

1. In what ways are learners' discussion posts qualitatively different when answered on an "open" platform or a "locked" platform?

2. How might differences in MOOC platform interfaces influence qualitative aspects of discussion posts? (i.e., "open" or "locked")

3.

\section{Method}

\section{Context}

We examined discussion posts from a data science ethics MOOC created by a large U.S. Midwestern university. The course presented issues related to the ethics of data and was intended for data scientists and decision-makers across any professional domain. The course offered a series of case study videos that provided a basis for engaging in discussion around issues such as who owns data and how we value privacy. The course also presented a framework for analyzing various issues, including how to approach data-driven algorithms and avoid unintended bias. The course consisted of eight modules, with one case study and discussion prompt per module.

\section{Participants}

Demographic data of learners across platforms were similar. On Coursera, roughly twothirds of learners were male, roughly half were between the ages of 25-39, and half had completed a master's degree before enrolling in the course. On edX, three-quarters of learners were male, just under half were between the ages of $25-39$, and $40 \%$ had completed a master's degree before taking the course.

\section{Data Sources}

We analyzed discussion posts from two modules of the course, called Prompts 1 and 2 in this study (see Appendix A). Prompt 1 was located in module two of the course and Prompt 2 was located in module six of the course. The first prompt asked learners to consider whether customers should be informed or give consent when a company uses their data to inform market strategy and a trade journal article. Our rationale for choosing this prompt was that the prompt asked learners to reason about a given problem, which would allow them to demonstrate critical thinking, going beyond information acquisition (the issue highlighted by Bonafini et al., 2017). The second prompt asked learners to express concerns about validity with respect to the design of a survey. Our rationale for selecting this prompt was similar in that the prompt asked learners to engage in a problem-solving activity. The discussion forums were not facilitated by an instructor, so instructor presence is not a relevant factor in our analysis.

We examined data from only the first six months that the course ran on each platform to eliminate the potential effects of a platform marketing intervention on one of the platforms where learners were essentially prompted to pay a small fee to continue in the course. The course was released "on demand," so all course materials and discussion prompts were available from the outset and for the full six months of our study. On edX, 6,058 learners enrolled and on Coursera 
1,204 learners enrolled during this six-month timeframe. We studied only direct responses to prompts because we wanted to understand how platform interfaces (i.e., "open" or "locked") might influence qualitative aspects of discussion posts at the point of interaction with the prompt itself. Our choice to study direct responses only relates to the instructional goal of providing discussion opportunities within the course, which was to offer learners an opportunity to engage with data science issues presented by the instructor through a video lecture. Although it may have been a hoped-for outcome, the prompts themselves did not extend an explicit invitation to learners to interact with other learners in the course.

Our dataset consisted of 110 Coursera posts and 16 edX posts for Prompt 1 and 54 Coursera posts and $14 \mathrm{edX}$ posts for Prompt 2. Enrollment was five times higher on edX than on Coursera, so it appears that there was a disproportionately low number of posts on edX compared with Coursera. We will elaborate on possible explanations for this difference in the discussion, including that Coursera's linear platform design makes it appear that learners must progress sequentially through all course items. Another reason could be that the visibility of all learners' posts on edX offers learners many posts to peruse, leaving them with less inclination or time to submit a response of their own.

\section{Approach to Analysis}

We employed a conventional content analysis, which starts with observation of the data and derives codes directly from the data (Hsieh \& Shannon, 2005). This method was well-suited to our study because existing literature on the intersection of platform interface and discussion post content is extremely limited. We collected and uploaded data into a cloud-based, qualitative software, which allows for collaborative coding by multiple users. The primary coder first created a preliminary codebook using an inductive and iterative approach to category creation (Thomas, 2006). They then coded 30 posts each from prompt 1 (alongside coder 2) and prompt 2 (alongside coder 3 ). After meeting and discussing the results, the primary and second coder established a pooled Cohen's kappa (de Vries et al., 2008) of 0.73 for question 1 using 30 different excerpts, and the primary and third coder established a pooled kappa of 0.89 for question 2 using another 20 excerpts. The second and third coders then coded the rest of the dataset for Prompts 1 and 2, respectively, using the finalized codebook (see Appendix B). We then used these final codings to calculate the mean, standard deviation, and confidence interval (at 95\%) for each platform-code combination. We compared results between the two platforms by conducting a two-tailed, two-sample t-test for each code.

\section{Results}

We now present qualitative characteristics of discussion posts on the "open" and "locked" platforms, organized by each prompt. As shown in Appendix A, prompt one described a mood manipulation experiment run by a social media platform and asked whether this company should inform users of this experiment and obtain consent before publishing results in a trade journal. Prompt two asked learners to surface validity concerns for a survey created by a parent company on user satisfaction of a product from a subsidiary company.

\section{Prompt One}

For prompt one, we coded whether learners addressed all aspects of the prompt completely, partially, or not at all. Our initial reading of the data showed that variation existed in the substantiveness of responses, so our analysis probed this difference with respect to "open" and "locked" platform interfaces. Learners who took the MOOC on the "locked" platform answered the prompt in its entirety more often than those on the "open" platform. 
Learners on the "open" platform failed to answer the prompt $37.5 \%$ of the time, whereas learners on the "locked" platform did not answer the prompt $7.3 \%$ of the time $(p<0.001$, indicating high statistical significance despite the small "open" platform sample size). Appendix B provides representative examples of each category: completely, partially, or not at all.

Our initial reading of the data suggested that the "degree of completeness" might relate to a learner's intent in engaging with the prompt. Our inductive approach to analysis culminated in three codes, and for each response we coded whether learners' intent was to complete the task, persuade, or reflect. Responses that were coded as "intent to complete the task" were generally succinct and to the point, without an explanation or reasoning behind the response. An example of a response that we coded as "intent to complete the task" reads: Yes, they should inform; yes, take consent. Responses that were coded as "intent to persuade" tended to use examples, explanations, or rhetorical moves to support a point of view. An excerpt of a response that we coded as "intent to persuade" reads:

I don't believe that Company X needs to inform its customers about this effort or obtain consent. Company $\mathrm{X}$ is doing a straight $\mathrm{A} / \mathrm{B}$ test - they are not conducting an experiment to see whether the stories change buying behavior.

An excerpt of a response that we coded as "reflect" reads: It could go either way but consent from the users would be good because this was affecting their emotions. On the "locked" platform, $31.8 \%$ of responses were coded as "intent to complete task," as opposed to $6.3 \%$ on the "open" platform $(p<0.05)$. Learners on the "open" platform demonstrated evidence of persuasion tactics and reflective writing.

Related to the idea that learners might have varying intentions when providing responses to discussion prompts, we also coded confidence levels, either assertive or tentative for each response. Responses that were coded as "assertive" used language that was sure and direct, without any indication of caution, indecisiveness, or ambiguity. Responses that were coded as "tentative" used hedging phrases such as "I think," "perhaps," and "it seems." Responses were generally more assertive on the "locked" platform (50.9\%) compared to the "open" platform (43.8\%), although we did not find this difference to be statistically significant.

\section{Prompt Two}

For prompt two, we generated a codebook that characterized various validity concerns surfaced by learners in their responses. Validity concerns encompassed some of the following: leading questions, sampling bias, participation bias, other types of selection bias, and poorquality responses (e.g., one- or two-word answers). Our codebook also included several learnergenerated improvements, such as including customers outside of the subsidiary company's customer base, alternative data collection methods, and restructuring of sampling methods. We observed a wider variety of responses on the "locked" platform, indicated by the fact that three of our codes $(n=12)$ only applied to this, and not the "open," platform. We also observed a unique phenomenon in the "open" platform where learners referred to others' posts, even within the direct responses to prompts we analyzed (as opposed to nested replies to others' responses). We would not have expected to see this behavior on the "locked" platform, since discussion posts of others did not become visible to learners until after submission. 


\section{Discussion}

The results of our analysis hint at some possible underlying explanations and their implications for learning design. Learners on the "open" platform may have failed to fully answer the prompt because they saw that other learners had already provided a valid response and therefore did not see value in reiterating what had already been said. Instead, they offered a different perspective that might have been complementary but could not be coded as "completely answers the prompt." We also witnessed reflection activity and persuasion tactics on the "open" platform. It is perhaps surprising that learners engaged in reflective activity in the presence of others (a somewhat personal endeavor), but they may have seen value in sharing formative ideas to engage in collective forms of inquiry, rather than individualistic ones. Additionally, as learners were aware of other perspectives, it is not surprising that they referenced existing ideas and engaged in persuasion tactics to convince others of the validity of their own views. While the present study did not examine learners' responses to other learners' posts (only direct responses to the prompt), the finding from Tan \& Quintana (2019) showing that the edX network had higher network centrality and cohesion is consistent with the idea that learners appeared to exhibit greater awareness of other learners in the course. On the "open" platform, we also saw that learners tended to use less assertive language than on the "locked" platform. A potential interpretation of the use of more tentative language used in responses may be that the "open" platform design caused learners to feel intimidated by the presence of other learners in the course. Poquet et al.'s (2018b) finding that MOOC learners experienced a low sense of familiarity, emotional connection, and trust regardless of cohort size, could support the assertion that learners on the "open" platform felt a sense of unease in the presence of other learners. Open platform interface designs may reinforce a learner's sense that they are engaging with unknown peers in a course.

Learners on the "locked" platform may have viewed posting responses to discussion prompts as a necessary task within a learning sequence. Learners may have perceived that providing a response was fulfilling a requirement that allowed them to move towards a goal of course completion. Although most MOOC platforms do not have a mechanism for instructors to grade the quality of discussion posts and generally do not allow discussion activity to count towards a final grade, the user interface of the "open" platform design may have made interaction with the discussion prompt seem less compulsory than that of the linear user interface on the "locked" platform design. Furthermore, the "locked" platform shows learners a green checkmark when an item is complete, further reinforcing a "completionist" mindset. We noted that responses on the locked platform had a more "assertive" level of confidence, using language that was clear and sure. Thus, the "locked" platform design seemed to cultivate attributes of efficiency and task completion. Tan et al.'s (2020) earlier finding that the most engaged learners on the Coursera platform were career motivated, rather than interest driven, supports the idea that learners on the "locked" platform had a more individualistic mindset. This finding is also consistent with Poquet et al.'s (2018a) research that suggested that "contemporary" MOOC learners are finding less value in using discussion forums as a space for social learning.

Our study shows that differences in platform interfaces do promote qualitative differences in discussion posts, which have the potential to impact learning. Our study also provides guidance for design teams on platform selection, relative to instructional goals. If it were important for every learner to engage directly with ideas presented, it would be worthwhile knowing that "open" platforms do not necessarily advance that goal. Instead, instructional teams might choose to use a "locked" platform design to advance that learning goal. If showcasing 
diversity of ideas shared within a community was a pedagogical goal (Scardamalia \& Bereiter, 2006), an "open" platform design might not achieve this, a somewhat counterintuitive finding. In fact, we found that learners on the "locked" platform also presented a wider range of ideas, which suggests that a productive instructional strategy could be to ask learners to engage with an idea individually before sharing with the larger community (as on Coursera). If providing opportunities for learners to make persuasive arguments was a critical instructional objective, then situating discussion prompts within an "open" platform could help achieve this goal. If an instructional objective is to promote deep reflection (Boud et al., 1985), a "locked" discussion forum design may not necessarily foster that activity, as learners interacting on this platform tend to adopt a "completionist" mindset.

Our study provides insight into how "open" and "locked" designs have the potential to shape the way learners respond to discussion prompts and can thus guide instructors towards making decisions about MOOC platforms and instructional activities situated within a learning sequence. Another productive outcome of this study could be to encourage MOOC platform providers to allow instructors and designers to choose whether a discussion prompt should be made "open" or "locked," depending on instructional goals for the activity or course. This would greatly increase the options available to design teams and would allow them to tailor activities to meet learning goals for a course. It would also give researchers greater insight into how aspects of MOOC interface designs can affect outcomes. Other novel platform configurations could include a "locked" forum where learners are shown peers' responses immediately after submitting their own response, followed by the opportunity to revise their original response. Since MOOC discussion forum interface designs have changed very little over the past few years, it would be beneficial to explore new options for deeper learning.

Our study contains some limitations, including a relatively small sample size with an uneven distribution of responses across platforms. Additionally, we only studied responses to two prompts from one MOOC. Given that there is limited research on the way discussion forum interfaces impact discussion post responses, we hope to build on the present study and conduct future research that examines other cases of MOOC discussion prompts hosted on multiple platforms.

\section{Acknowledgements}

The authors would like to acknowledge the contributions of Kelly Chan, who assisted in the preparation of the manuscript. Additionally, the authors would like to thank Sadia Nawaz who provided thoughtful comments and suggestions on an early draft of the manuscript.

\section{Declarations}

The authors declared no potential conflicts of interest with respect to the research, authorship, and/or publication of this article.

The authors received approval from the ethics review board of the University of Michigan, USA for this study.

The author received no financial support for the research, authorship, and/or publication of this article. 


\section{References}

Almatrafi, O., \& Johri, A. (2018). Systematic review of discussion forums in massive open online courses (MOOCs). IEEE Transactions on Learning Technologies, 12(3), 413-428.

Azhar, T. F., \& Santoso, H. B. (2019). Evaluation of instructional and user interface design for MOOC: Short and free FutureLearn courses. In the 2019 International Conference on Advanced Computer Science and Information Systems (ICACSIS) (pp. 425-434). IEEE.

Bonafini, F. C., Chae, C., Park, E., \& Jablokow, K. W. (2017). How much does student engagement with videos and forums in a MOOC affect their achievement? Online Learning, 21(4), 223-240. http://dx.doi.org/10.24059/olj.v21i4.1270

Boud, D., Keogh, R., \& Walker, D. (Eds.). (1985). Reflection: Turning experience into learning. Kogan Page.

Bruff, D. O., Fisher, D. H., McEwen, K. E., \& Smith, B. E. (2013). Wrapping a MOOC: Student perceptions of an experiment in blended learning. Journal of Online Learning and Teaching, 9(2), 187.

Chandrasekaran, M. K., Kan, M., Tan, B. C., \& Ragupathi, K. (2015). Learning instructor intervention from MOOC forums: Early results and issues. Proceedings of the 8th international conference on education data mining, pp. 218-225.

Cohen, D. K., Raudenbush, S. W., \& Ball, D. L. (2003). Resources, instruction, and research. Educational evaluation and policy analysis, 25(2), 119-142.

Conole, G. (2014). A new classification schema for MOOCs. The International Journal for Innovation and Quality in Learning, 2(3), 65-77.

Coursera: Take the world's best courses, online. (n.d.). Retrieved August 14, 2020, from http://www.coursera.org

De Vries, H., Elliott, M. N., Kanouse, D. E., \& Teleki, S. S. (2008). Using pooled kappa to summarize interrater agreement across many items. Field Methods, 20(3), 272-282.

Dowell, N., Poquet, O., \& Brooks, C. (2018). Applying group communication analysis to educational discourse interactions at scale. In J. Kay and R. Luckin, (Eds.), Rethinking Learning in the Digital Age: Making the Learning Sciences Count, 13th International Conference of the Learning Sciences (ICLS) 2018, Volume 3. London, UK: International Society of the Learning Sciences.

Downes, S. (2009, February 24). Connectivist dynamics in communities. Half an Hour. http://halfanhour.blogspot.co.uk/2009/02/connectivist-dynamics-in-communities.html

Edx: Free Online Courses by Harvard, MIT, \& More, online. (n.d.). Retrieved August 14, 2020, from https://www.edx.org/ 
Eisenberg, M., \& Fischer, G. (2014). MOOCs: A perspective from the learning sciences. Proceedings of the 11th International Conference of the Learning Sciences (ICLS), 190-197

Emanuel, J. P., \& Lamb, A. (2017). Open, online, and blended: transactional interactions with MOOC content by learners in three different course formats, Online Learning 21 (2). http://dx.doi.org/10.24059/olj.v21i2.845

Ferguson, R., \& Sharples, M. (2014). Innovative pedagogy at massive scale: teaching and learning in MOOCs. In European Conference on Technology Enhanced Learning (pp. 98-111). Springer.

Glory, C., \& Santoso, H. B. (2019). Evaluation and recommendations for edX MOOC platform based on instructional design and interaction design principles. In 2019 International Conference on Advanced Computer Science and Information Systems (ICACSIS) (pp. 441-450). IEEE.

Håklev, S., \& Slotta, J. D. (2017, May). A principled approach to the design of collaborative MOOC curricula. In European Conference on Massive Open Online Courses (pp. 58-67). Springer, Cham.

Hanifa, M. R., \& Santoso, H. B. (2019). Evaluation and recommendations for the instructional design and user interface design of Coursera MOOC platform. In the 2019 International Conference on Advanced Computer Science and Information Systems (ICACSIS) (pp. 417-424). IEEE.

Hara, N., Bonk, C. J. \& Angeli, C. (2000). Content analysis of online discussion in an applied educational psychology course. Instructional Science 28, 115-152. https://doi.org/10.1023/A:1003764722829

Hsieh, H. F., \& Shannon, S. E. (2005). Three approaches to qualitative content analysis. Qualitative Health Research, 15(9), 1277-1288. https://doi.org/10.1177/1049732305276687

Kellogg, S., Booth, S., \& Oliver, K. (2014). A social network perspective on peer supported learning in MOOCs for educators. The International Review of Research in Open and Distributed Learning, 15(5). https://doi.org/10.19173/irrodl.v15i5.1852

Oktavia, T., Prabowo, H., \& Supangkat, S. H. (2018). The comparison of MOOC (massive open online course) platforms of edx and coursera (Study case: Student of programming courses). In 2018 International Conference on Information Management and Technology (ICIMTech) (pp. 339-344). IEEE.

Poquet, O., Dowell, N., Brooks, C., \& Dawson, S. (2018a). Are MOOC forums changing? LAK '18 Proceedings of the 8th International Conference on Learning Analytics and Knowledge, pp. 340-349. http:// dx.doi.org/10.1145/3170358.3170416. 
Poquet, O., Kovanovic, V., Hennis, T., de Vries, P., Joksimovic, S., Gasevic, D., \& Dawson, S. Social presence in Massive Open Online Courses. (2018b). International Journal of Research in Open and Distributed Learning, 19(3). http://dx.doi.org/10.19173/irrodl.v19i3.3370

Quintana, R. M., Hearn, C., Peurach, D. J., \& Gabriele, K. (2020). Self-directed, communitysupported learning in practice: A case of elevated support. In L. Wilton \& C. Brett (Eds.), Handbook on research on online discussion-based teaching methods (pp. 312-332). IGI Global.

Quintana, R. M., \& Tan, Y. (2021). Visualizing course structure: Using course composition diagrams to reflect on design. Tech Trends, 65, 562-575. https://doi.org/10.1007/s11528-02100592-x

Scardamalia, M., \& Bereiter, C. (2006). Knowledge building: Theory, pedagogy, and technology. In K. Sawyer (Ed.), Cambridge Handbook of the Learning Sciences (pp. 97-118). Cambridge University Press.

Tan, Y., \& Quintana, R. M. (2019, March). What can we learn about learner interaction when one course is hosted on two MOOC platforms? Proceedings of the 9th International Conference on Learning Analytics and Knowledge (LAK). (pp. 149-150). Tempe, Arizona.

Tan, Y., Quintana, R. M., \& Sohn, J. (2020, April). Cross-platform engagement in MOOCs: Understanding learner audiences on two course delivery platforms. Poster accepted to the Annual Meeting of the American Educational Research Association (AERA). Conference Cancelled.

Thomas, D. R. (2006). A general inductive approach for analyzing qualitative evaluation data. American Journal of Evaluation, 27(2), 237-246.

Tsironis, A., Katsanos, C., \& Xenos, M. (2016). Comparative usability evaluation of three popular MOOC platforms. 2016 IEEE Global Engineering Education Conference (EDUCON) (pp. 608-612). IEEE.

Wong, J. S., Pursel, B., Divinsky, A., \& Jansen, B. J. (2015). Analyzing MOOC discussion forum messages to identify cognitive learning information exchanges. Proceedings of the Association for Information Science and Technology, 52(1), 1-10.

https://doi.org/10.1002/pra2.2015.145052010023 


\section{Appendix A}

Prompts 1 and 2 were the basis of discussion posts we examined in this study

\section{Prompt 1}

Company X has learned about Facebook's mood manipulation experiment and believes that a happy person is much more likely to buy than a grumpy one. Therefore, it has designed its web site to tell heart-warming stories in callout boxes on every page. These stories, at best, are tangentially related to the products being sold on the page. They A/B test this website before launch to see if the story boxes do have the intended effect. They find that the boxes do have the desired effect of increasing sales. They then adopt the new website design with the story boxes, and they write an article describing their findings in a Marketing Journal.

- Does Company X need to inform its customers about this effort? To what extent?

- Does it need to obtain consent? If so, for what?

If you answered YES to the consent question above, what is the smallest change to the scenario described above that would make you change your answer to NO.

\section{Prompt 2}

Seeking to expand their business and improve their product, suppose that Amazon sends a survey to all Kindle owners asking them what they like and dislike about their Kindle. What validity concerns would you have about the survey results obtained? If the primary goal is to grow Kindle sales, what could Amazon do to get more valid data. 


\section{Appendix B}

\section{Codebook for Posts in Prompt 1}

\begin{tabular}{|c|c|c|}
\hline Code & Description & Example(s) \\
\hline $\begin{array}{l}\text { Answers } \\
\text { prompt: Yes }\end{array}$ & $\begin{array}{l}\text { The response fully answers the question(s) } \\
\text { in the prompt. It includes a response to the } \\
\text { two main questions included in the prompt } \\
\text { (i.e., a reference to inform and to consent). }\end{array}$ & $\begin{array}{l}\text { I don't believe that Company X needs to inform } \\
\text { its customers about this effort or obtain } \\
\text { consent. Company X is doing a straight A/B } \\
\text { test-they are not conducting an experiment to } \\
\text { see whether the stories change buying } \\
\text { behavior-rather they assume that this is true } \\
\text { at the start based on Facebook's experiment } \\
\text { and are simply comparing two website } \\
\text { designs-with and without stories-and } \\
\text { measuring which drives greater sales. }\end{array}$ \\
\hline
\end{tabular}

Answers The response does not fully answer the prompt: No question(s) in the prompt.

Answers

prompt:

Partially

Intent:

Complete task

Intent:

Persuade

Intent: Reflect
The response indicates that the learner simply wanted to complete the task. These responses are often succinct and to the point, with no explanation of the reasoning behind the response.

The response indicates that the learner is trying to persuade others as to why they are correct. These responses may use explanations, examples, and/or rhetorical moves to prove a point.

The response indicates that the learner is using this space as a self-reflection of their own thought processes. These responses are often written in a stream-ofconsciousness style. They may also consider opposing views in a sort of selfdialogue.
I think the ethical problem is not so much the experiment, but what the limits are to manipulating the weaknesses of humans into buying stuff. For instance, the idea that pictures of your friends and family can be used to generate a personalised advertisement. It will subconsciously cause you to believe the message because your brain recognises your friends' trades. That is unethical.

Yes, I think Company X needs to inform its customers about the experiment so that they can have a right to withdraw if need be.

Yes, they should inform. Yes, take consent.

I don't believe that Company X needs to inform its customers about this effort or obtain consent. Company $X$ is doing a straight $A / B$ test-they are not conducting an experiment to see whether the stories change buying behavior-rather they assume that this is true at the start based on Facebook's experiment and are simply comparing two website designs - with and without stories - and measuring which drives greater sales. Ifeel like the people in this experiment should have been notified. Although I feel like it should be a very vague notification, so it doesn't mess with the data. It could go either way but consent from the users would be good because this was affecting their emotions. I would have added a small page that would ask you if you would like to participate in a test but be vague. 
Confidence: The response uses language that is sure Assertive

Confidence: Tentative

Examples: External

Examples: Internal and direct.

The response uses language that is not entirely certain of itself, such as "I think," "perhaps," "it seems," etc.

The response uses examples not found in completed parts of the course.
The company does not have to obtain consent from its customers in this scenario. They did not obtain any customer info per se, and any action on behalf of the customer was of their own informed accord. The action of the company to use feel-good stories to accompany their product pitches is the very essence of the discipline known as 'marketing.'

I think the company should provide a statement in their terms of use letting the public know that they will use their data to improve the site (this would include improving sales). I think this is standard business practice and is understood (i.e., ethical). Publishing in a journal is research and requires informed consent.

If they are not lying, the practice is acceptable. Turn on your TV set and look at any ad. My favorite example at this moment is for a product being pitched to people with non-small cell sarcoma of the lung, which if you read the fine print accompanying the ad says that in clinical trials it raised the lifetimes

of the subjects on the average by 3 months. The ad shows happy, smiling people, and repeatedly promises a longer life. In reality, someone with end stage lung cancer is not out walking around or watching baseball games. Is the ad ethical? Absolutely. It makes no false promises or claims. Is it realistic? No less so than the ad for the baldness product that shows the 'after' guy hand in hand with a beautiful woman. I challenge my fellow students to cite a single example of an advertisement that does not attempt to place the viewer or reader in a happy mood. Some of the most successful ads in all history were ones that were simply humorous, barely even mentioning or showing the product being sold. For those of you old enough to remember, VW beetle ads; Alka-Seltzer.

There is a fine line between research and business though. For business purposes you are not required to explicitly ask for consent. But after Facebook and OKCupid's experiment, and the backlash they faced, it makes sense to have this written in the terms of service/privacy agreement. 
References other posts

The response refers to other posts in the same module.
I think this sort of thing is fine, and it's primarily because of context. A company website exists first and foremost to sell the company's products, so anyone visiting the website may reasonably expect to be marketed to. Even small improvements in the UI can lead to more 'desirable' (i.e., buying) behavior, and these are common and wellresearched tactics as well. I think it would become unacceptable if the company strongly implied that these were testimonials; or lied about the tactics when directly questioned; or as $R \_$Streeter said, didn't anonymize the information.

\section{Codebook for posts in Prompt 2}

\begin{tabular}{|c|c|c|}
\hline Code & Description & Example(s) \\
\hline $\begin{array}{l}\text { Validity concerns: } \\
\text { Sampling bias }\end{array}$ & $\begin{array}{l}\text { The surveyed sample isn't } \\
\text { representative of the target } \\
\text { population, or the surveying } \\
\text { method itself is otherwise } \\
\text { problematic. For example, only } \\
\text { surveying existing Kindle } \\
\text { customers negatively impacts } \\
\text { validity. }\end{array}$ & $\begin{array}{l}\text { My primary validity concern would be the } \\
\text { choice of a representative sample. Current } \\
\text { Kindle owners will probably not be } \\
\text { representative of the (potential) user groups } \\
\text { Amazon would like to sell new Kindle's. }\end{array}$ \\
\hline $\begin{array}{l}\text { Validity concerns: } \\
\text { Participation bias }\end{array}$ & $\begin{array}{l}\text { Similar to sampling bias, but in this } \\
\text { case the unbalanced representation } \\
\text { arises from people choosing to } \\
\text { participate or not. Those who choose } \\
\text { to respond may share attributes not } \\
\text { representative of the target } \\
\text { population. }\end{array}$ & $\begin{array}{l}\text { Persons who are very happy or very unhappy } \\
\text { with their Kindle may be more inclined to } \\
\text { respond versus those who don't feel as strongly } \\
\text { one way or another. The unbalanced response } \\
\text { rates might affect validity. }\end{array}$ \\
\hline
\end{tabular}


Validity concerns:

Other selection biases

Validity concerns:

Poor-quality responses

Validity concerns:

Leading questions

Improving validity: Include non-Kindleowners

Improving validity:

Alter sampled group in other ways

Improving validity: Survey content/design suggestions

Improving validity: Alternatives to surveys
Other validity concerns dealing with the group that is being surveyed.

Examples include:

- Respondents may rarely use their Kindles

- Kindle customers may not be the consumers

- Kindle model differences

- Possibility of low response rates

- Customer saturation

The quality of the responses themselves may lead to questionable validity.

Examples include:

- Skewed results based on current events

- Subjective responses

- Purposefully misleading responses

Asking questions on the survey that may sway participants to answer in a specific way.

The survey should also be sent to people who don't already own a Kindle.

Examples include:

- Target other Amazon customers

- Target regular book readers

The surveyed group should be modified in other ways.

Examples include:

- Ideas for increasing response rate

- Survey newer Kindle owners

Specific suggestions for the types of questions that should be asked on the survey or the survey's design to improve validity.

An alternative data-collection method should be consideredsomething different than surveys.
The first validity concern (supposing that the survey is sent via an email which could be accessed in any device) would be if it is sent to the correct person i.e., it should be a current and active user of the device for a relatively accurate response. If the survey is sent to an in-built kindle application, then the above thing won't be a concern. So supposing the second possibility the next validity concern would be of demographics. If the survey doesn't collect info like sex, age, ethnicity and even income levels then the survey data would have to be taken as a very broad based data set which won't be useful for them to customise their product for target groups.

Secondly, this method will yield subjective data-only things the users are aware of, sometimes possibly being a hypothesis that is not true.

Furthermore, some users (competitors?) might intentionally enter incorrect data.

Asking users what is liked and disliked will likely steer users away from a neutral rating, compared to asking users to merely give their reflections about their purchase.

I'd advise Amazon to include a random sample of all Amazon users to get more valid data. This sample will be more representative of all people that might be interested in buying a Kindle.

Amazon could offer a gift card to have focus groups done where they can select the demographics they want to know more about.

Amazon could ask to every amazon user that doesn't buy a kindle device if there is a reason why they did not, and if they have bought another eBook reader, why they preferred it to the kindle, and of course, to those that have bought it, if there is something that they would change or improve in a future version.

To get data that was more valid, Amazon could invite non-users to participate in paid focus groups or demos where they used a Kindle and shared about their experience. 
Improving validity: Control for representation biases in the analysis
The analysis stage of the study should include ways to account for representation biases in the sample. This often includes taking varying demographics into account.
Improving validity: Considerations regarding the Anonymous/ confidential feedback/data

Additional points not directly related to validity:
The learner's response includes suggestions/thoughts that are unrelated to the validity of the proposed study.

\begin{abstract}
Amazon must make a random sampling of those who have Kindle and still use it. Segmentation must be based on location, age, gender, education level, occupation, income range and the model that they bought as. Societal practices may be relevant to usage patterns, occupation is necessary as some professions require a lot of reading while certain others read out of interest. Similarly medical certain conditions that happened after purchase of Kindle that prevent them now from using Kindle comfortably needs to be taken into consideration. The segmented population must be weighted when the number isn't equal it's most often unlikely to have an equal number.
\end{abstract}

Confidentiality must be assured and that details collected will not be sold to third parties or be used for other purposes not meant for at the time of data collection.

Among the responses, Amazon can find some that have a good suggestion on how to improve the product. In this sense, the survey can provide valid input. 